\title{
Research on the Canonical Correlation between Employment and Economic Development in China
}

\author{
Jie WANG ${ }^{1, a}$ and Hong-Mei $\mathrm{LI}^{2, \mathrm{~b}}$ \\ ${ }^{1}$ North China University of Technology, Beijing, China \\ ${ }^{2}$ North China University of Technology, Beijing, China \\ a1060800534@qq.com, 'blhmei6280@163.com
}

Keywords: Employment, Economic Development, Tertiary Industry, Corresponding Analysis, Canonical Correlation Analysis.

\begin{abstract}
As China's labor resources and employment problems become more and more serious, it is crucial that exploring the relationship between employment and economic development. Through corresponding analysis, we conclude that the developed cities are dominated by the tertiary industry and employees in these areas are generally highly educated. In addition, we use a canonical correlation analysis to analyze the relationship between employment and economic development. The results show that: the per capita GDP, the investment in education funds and the economic proportion of the tertiary industry are closely related to the average employment wage and structure.
\end{abstract}

\section{Introduction}

With the decline of China's birth rate and the extension of life expectancy, the age structure of China's population has profound changes, and the problems of employment and demographic dividends have emerged one after another. In response to the problems, the state has introduced a progressive delayed retirement age policy and a policy of adjusting family planning. Also, through the study of scholars at home and abroad, it is found that the level of employment is crucial for the development stability of a country, and the employment structure and the labor force quality especially are closely related to the level of economic development. Therefore, this paper will propose relevant suggestions and measures for the coordinated development of employment and economy by exploring the relationship between employment and economic development in China.

\section{Overview of Employment and Economic Development}

\section{Employment Structure}

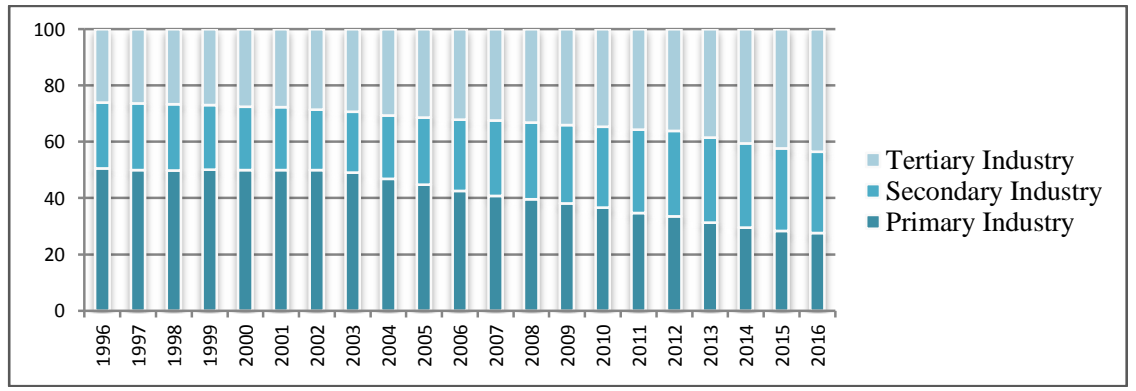

Figure 1. The employment structure of China's Industrial [\%] 
Fig. 1 shows the distribution of the employment structure in China from 1996 to 2016. Overall, employees have gradually shifted from the primary industry to the tertiary industry. This reduces the employment proportion of the primary industry but increases the proportion of tertiary and secondary industry.

\section{The Employment Level of Education}

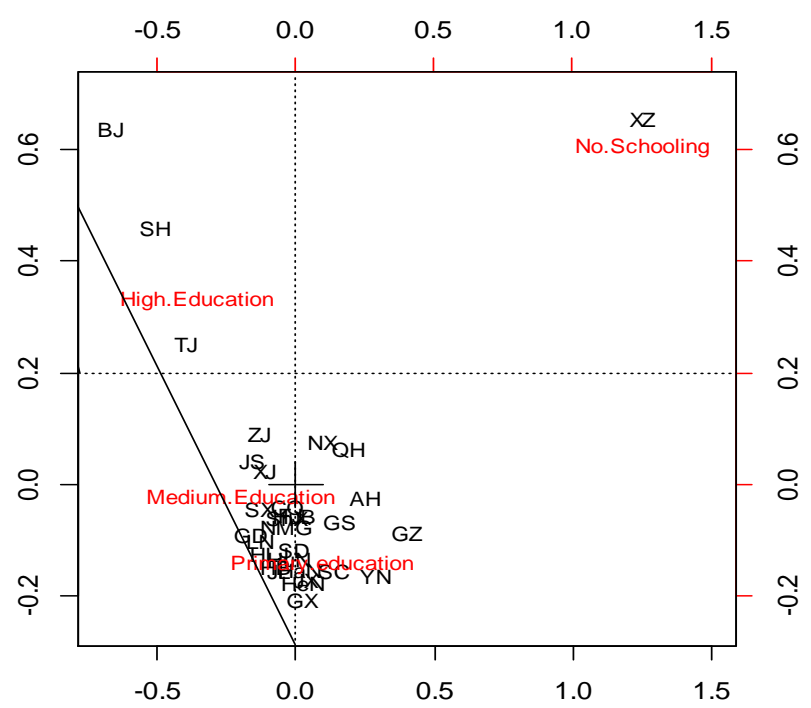

Figure 2. Educational attainment of employed persons by region

Fig. 2 is a corresponding analysis graph of the education level of 31 provinces and cities in China in 2015. It can be seen that the employees in large cities such as Beijing, Shanghai and Tianjin are generally highly educated, while the average education level of employees in Tibet is low, mainly due to the remote location and the poor educational resources.

\section{The Distribution of Industrial Structure}

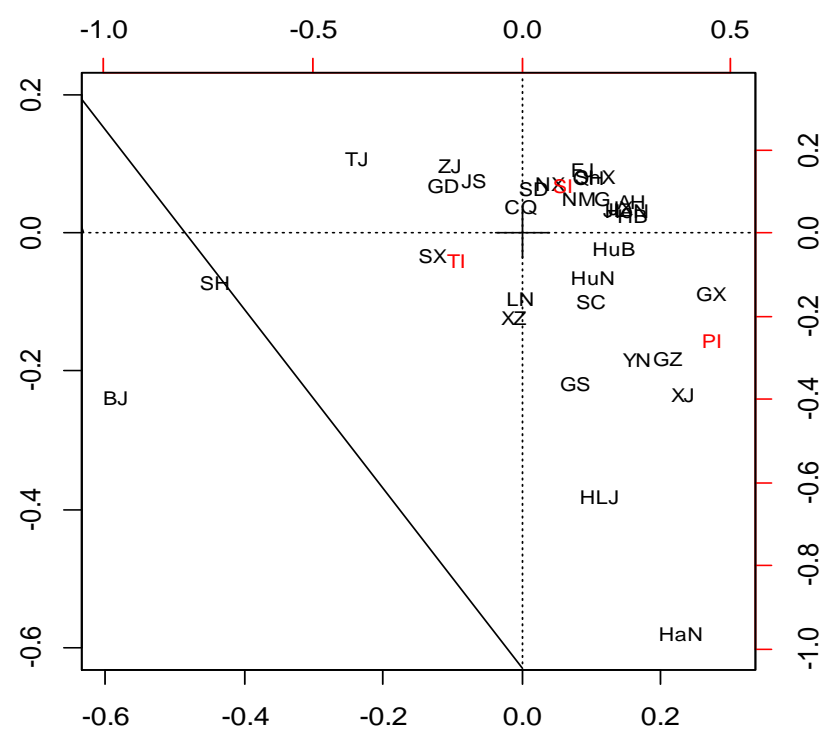

Figure 3. Industrial structure of China 
Fig. 3 shows the corresponding analysis graph of China's regional and industrial structure. It can be seen that the leading industry in the provinces and cities with rapid economic development, such as Beijing, Shanghai and Guangdong, is the tertiary industry.

\section{Empirical Analysis of the Relationship between Employment and Economic Development}

\section{Indicator Design and Data Selection}

According to the above analysis, we choose three variables to describe the employment situation: Employment Rate, average Salary and Employment Structure. Meanwhile, four indicators of the economic development are selected: Per Capita GDP, Economic Structure, Economic Activity Population, and Educational Funding. The variable definitions are as follows:

Table 1.Employment Indicator

\begin{tabular}{|l|c|l|}
\hline Variable name & Variable symbol & Variable definition \\
\hline Employment Rate & $\mathrm{X} 1$ & $\begin{array}{l}\text { Employed Population } \\
\text { / Economically Active Population [\%] }\end{array}$ \\
\hline Average Salary & $\mathrm{X} 2$ & $\begin{array}{l}\text { Average Wage of Employed Persons } \\
\text { [Ten Thousand Yuan] }\end{array}$ \\
\hline Employment Structure & $\mathrm{X} 3$ & $\begin{array}{l}\text { Employees in Tertiary Industry } \\
\text { / Total Employees [\%] }\end{array}$ \\
\hline
\end{tabular}

Table 2.Economic development indicator

\begin{tabular}{|l|c|l|}
\hline Variable name & Variable symbol & Variable definition \\
\hline Per Capita GDP & Y1 & Per Capita GDP [Yuan] \\
\hline Economic Structure & Y2 & $\begin{array}{l}\text { Tertiary Industry Gross Production/ } \\
\text { GDP [\%] }\end{array}$ \\
\hline $\begin{array}{l}\text { Economic Activity } \\
\text { Population }\end{array}$ & Y3 & $\begin{array}{l}\text { Economically Active Population / Total } \\
\text { Population [\%] }\end{array}$ \\
\hline Educational Funding & Y4 & $\begin{array}{l}\text { Fiscal Education Expenditure/ GDP } \\
{[\%]}\end{array}$ \\
\hline
\end{tabular}

\section{Canonical Correlation Analysis of Employment and Economic Development}

Based on the data of employment and economic indicators from 1996 to 2015 in the National Statistical Yearbook, employing the R programming language, we use Canonical Correlation Analysis to explore the relationship between employment and economic development.

\section{1) Canonical correlation coefficient}

As shown in the following table, we obtain the correlation coefficient matrix of the sample, and divide it (such as formula 1), and then obtain the eigenvalues and canonical correlation coefficient. 
$\mathrm{R}=\left[\begin{array}{ll}\mathrm{R}_{11} & \mathrm{R}_{12} \\ \mathrm{R}_{21} & \mathrm{R}_{22}\end{array}\right]$

Table 3. Sample correlation coefficient matrix

\begin{tabular}{|c|c|c|c|c|c|c|c|}
\hline & $\mathrm{X} 1$ & $\mathrm{X} 2$ & $\mathrm{X} 3$ & $\mathrm{Y} 1$ & $\mathrm{Y} 2$ & $\mathrm{Y} 3$ & $\mathrm{Y} 4$ \\
\hline $\mathrm{X} 1$ & 1.0000 & 0.6605 & 0.7306 & 0.7056 & 0.7504 & 0.6466 & 0.6630 \\
\hline $\mathrm{X} 2$ & 0.6605 & 1.0000 & 0.9874 & 0.9966 & 0.9005 & 0.6188 & 0.9784 \\
\hline $\mathrm{X} 3$ & 0.7306 & 0.9874 & 1.0000 & 0.9882 & 0.9245 & 0.6397 & 0.9501 \\
\hline $\mathrm{Y} 1$ & 0.7056 & 0.9966 & 0.9882 & 1.0000 & 0.9080 & 0.6445 & 0.9796 \\
\hline $\mathrm{Y} 2$ & 0.7504 & 0.9005 & 0.9245 & 0.9080 & 1.0000 & 0.7907 & 0.9070 \\
\hline $\mathrm{Y} 3$ & 0.6466 & 0.6188 & 0.6397 & 0.6445 & 0.7907 & 1.0000 & 0.6537 \\
\hline $\mathrm{Y} 4$ & 0.6630 & 0.9784 & 0.9501 & 0.9796 & 0.9070 & 0.6537 & 1.000 \\
\hline
\end{tabular}

\section{2) Canonical correlation results}

We calculate the correlation coefficient and learn that two pairs of canonical variables are 0.9990269 and 0.9314684 , which are highly canonical correlated between these variables. As a result, the first two pairs of canonical variables pass the significance test of the canonical correlation coefficient, that is, the first two canonical correlations are significant at the $\alpha=0.05$ level. Therefore, these canonical variables are subsequently analyzed.

Table 4. The fitting result of canonical coefficient of employment indicators

\begin{tabular}{|c|c|c|c|}
\hline & {$[, 1]$} & {$[, 2]$} & {$[, 3]$} \\
\hline $\mathrm{X} 1$ & -0.02683766 & -0.1265958 & -0.3859672 \\
\hline $\mathrm{X} 2$ & 0.29103038 & 1.6649262 & 0.4798052 \\
\hline $\mathrm{X} 3$ & -0.08085782 & -1.7751045 & -0.7588127 \\
\hline
\end{tabular}

Table 5. canonical coefficient of economic development indicators

\begin{tabular}{|c|c|c|c|c|}
\hline & {$[, 1]$} & {$[, 2]$} & {$[, 3]$} & {$[, 4]$} \\
\hline Y1 & 0.198986570 & -0.62497643 & -0.26476013 & 0.9537819 \\
\hline Y2 & -0.002045967 & -0.45405804 & -0.05834397 & -0.5584643 \\
\hline Y3 & -0.003949248 & 0.08511912 & 0.31375151 & 0.2175418 \\
\hline Y4 & 0.035434708 & 0.99667569 & 0.11978572 & -0.5951447 \\
\hline
\end{tabular}

From Table 4 and Table 5, we conclude that:

The first pair of canonical correlation variables is expressed as:

$\left\{\mathrm{U}_{1}=-0.02683766 \mathrm{X}_{1}+0.29103038 \mathrm{X}_{2}-0.08085782 \mathrm{X}_{3}\right.$

$\left\{\mathrm{V}_{1}=0.198986570 \mathrm{Y}_{1}-0.002045967 \mathrm{Y}_{2}-0.003949248 \mathrm{Y}_{3}+0.035434708 \mathrm{Y}_{4}\right.$.

In formula (2), $U_{1}$ is a linear combination of employment in China, where $X_{2}$ has a larger load than $X_{1}$ and $X_{3}$, which indicating the average wage of employed persons on employment contributes the most; $V_{1}$ is a linear combination of economic development level indicators, 
where the variable with large load is $\mathrm{Y}_{1}$, followed by $\mathrm{Y}_{4}, \mathrm{Y} 3$ and $\mathrm{Y}_{2}$. This shows that in the canonical correlation between employment and economic development, Per Capita GDP is closely related to the average wage of employees.

The second pair of canonical correlation variables is expressed as:

$$
\left\{\begin{array}{l}
U_{2}=-0.1265958 X_{1}+1.6649262 X_{2}-1.7751045 X_{3} \\
V_{2}=-0.62497643 Y_{1}-0.45405804 Y_{2}+0.08511912 Y_{3}+0.99667569 Y_{4}
\end{array}\right.
$$

According to the principle of canonical correlation analysis, the canonical variables $\mathrm{U}_{2}$ and $\mathrm{V}_{2}$ are not related to $\mathrm{U}_{1}$ and $\mathrm{V}_{1}$. That is, the second pair of canonical correlation variables has the greatest degree of correlation after eliminating the information contained in $U_{1}$ and $V_{1}$.

Formula (3) shows that in the employment indicators, $X_{2}$ and $X_{3}$ have a larger load than $X_{1}$, and hence we use $X_{2}$ and $X_{3}$ as the first group. Among the economic level indicators, $Y_{4}, Y_{1}$ and $Y_{2}$ have a larger load than $Y_{3}$, so we use $Y_{4}, Y_{1}$ and $Y_{2}$ as the second group. Therefore, we conclude that there is a significant correlation between the two groups.

\section{3) Score equivalent plan}
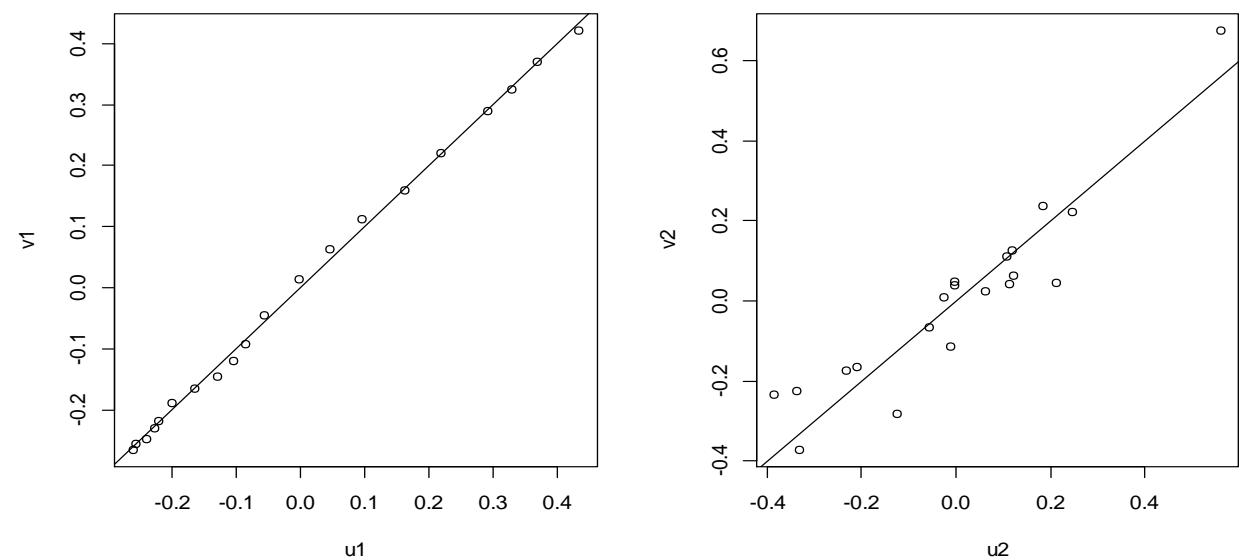

Figure 4. Scoring equivalence plan between $U$ and V

It can be seen from the scored equivalence plan of canonical correlation variables in Fig.4 that the scatters of the first pair of canonical correlation variables are distributed on an approximate straight line, $\mathrm{U}_{1}$ and $\mathrm{V}_{1}$ are highly linearly related; also, the scatters of the second pair of canonical correlation variables is slightly deviated, but the overall trend is linear. Therefore, the relationship between employment and economic development level in China is stable and the overall fluctuation is stable.

In summary, the employment in China is closely related to the level of economic development. The increase in per capita GDP, the increase in national education funding and the contribution of the tertiary industry to the economy can promote the average wages and the proportion of employment in the tertiary industry.

\section{Conclusion}

Based on the above analysis, the following conclusions are drawn:

The relationship between employment and economic development level in China is relatively stable. Among them, Per Capita GDP, Educational Funding Ratio and Economic Structure are closely related to Average Wage and Employment Structure. 
Thanks to the economic development and technological progress, the importance of the tertiary industry to economic development is increasing day by day. The tertiary industry, which is mainly based on the service industry, will replace the primary industry dominated by agriculture, and becomes China's leading industry. To improve domestic employment situation, China should accelerate industrial transformation from labor-intensive to technology-intensive. It is important to promote the flow of labor from primary and secondary industry to tertiary industry by improving productivity, which means replacing the labor force in primary and second industries with machines. This transformation will contribute to economic development, which can help to improve the state of employment simultaneously.

The employees in developed areas generally have a higher education, and which in remote areas have a lower one. So, firstly, the nation and local governments should pay attention to education and training, and provide high-ability and high-level talents to the society, in order to improve the employment skills of employees. Secondly, we should put more resources into the remote provinces, increase the education penetration rate gradually, and develop the employment skills, thereby increasing employment opportunities, reducing unemployment rate, and ensuring economic development and long-term social stability.

\section{Acknowledgment}

This research was financially supported by 2018 project of education and teaching reform of North China University of Technology. (No.109051360018XN009/096)

\section{References}

[1] Mehrnoosh Mohseni; Feizolah Jouzaryan. Examining the Effects of Inflation and Unemployment on Economic Growth in Iran (1996-2012). [J]. Elsevier journal, 2016:381-389.

[2] Li Haizhen, Tang Wei. Regional differences in labor quality based on human capital [A]. Journal of Central University of Finance and Economics, 2015(8): 72-86.

[3] Chen Bo, Wu Lili. The Relationship between Demographic Dividend, Labor Quality and Medium and Long Term Economic Growth [J]. Public Administration, 2011(6): 152-159.

[4] Jing Yuejun, Zhang Wei. Analysis of the Correlation and Coordination of Labor Employment Structure and Industrial Structure in China [A]. Population Journal, 2015.213(37): 85-93.

[5] Meng Lijun. China's Economic Growth and Cyclical Changes---Analysis of Economic Status and Prospects from GDP Growth Rate [J]. Modern Business, 2015(24): 93-94.

[6] Fei Yu, Guo Minzhi. Multivariate Statistical Analysis with R [M]. Beijing: China Renmin University Press,2014.(In Chinese)

[7] N.gregory mankiw, translated by Liang Xiaomin, Liang Li. Principles of Economics (7th edition). [M]. Beijing: Peking University Press, 2015. (In Chinese) 